\title{
ChemComm
}

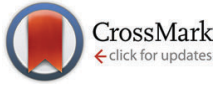

Cite this: Chem. Commun., 2015, 51,5402

Received 2nd November 2014, Accepted 16th December 2014

DOI: $10.1039 / \mathrm{c} 4 \mathrm{cc} 08718 \mathrm{f}$

www.rsc.org/chemcomm

\section{Neptunyl(vi) centred visible LMCT emission directly observable in the presence of uranyl(vi) $\dagger$}

\author{
Sean D. Woodall, ${ }^{a}$ Adam N. Swinburne, ${ }^{\text {ab }}$ Nidhu lal Banik, ${ }^{c}$ Andrew Kerridge, $\ddagger^{\mathrm{e}}$ \\ Poppy Di Pietro, ${ }^{e}$ Christian Adam, ${ }^{c d}$ Peter Kaden ${ }^{c}$ and Louise S. Natrajan ${ }^{\star a b}$
}

\begin{abstract}
Room temperature detection of neptunyl(vi) LMCT emission in a coordination compound and in the presence of uranyl(v) is reported for the first time. Differences in the excitation profiles of the complexes enable spectral editing so either exclusively neptunyl(vi) or uranyl(vi) emission is observed or a sum of the two.
\end{abstract}

There is an urgent need to address the many environmental problems the nuclear age has brought about; in particular, the identification of (trace) radiotoxic actinide ions, their oxidation state and chemical form. ${ }^{1}$ In this regard, time resolved emission spectroscopy is becoming an invaluable tool with which to probe the electronic structure (oxidation state and coordination environment) of a given actinide ion in low concentrations that may represent those encountered in environmental and reprocessing conditions. ${ }^{2}$

The seminal work of Denning, ${ }^{3}$ amongst others, utilised the emissive properties of the uranyl(vi) ion to help construct the molecular orbital bonding diagram widely used today. However, corresponding studies on its periodic neighbour neptunyl(vi) are very limited. ${ }^{4}$ Currently, time-resolved spectroscopic studies of the uranyl(vi) ion are often used to provide valuable insight into the speciation of uranium species on minerals and sediments, ${ }^{5}$ particularly those present in geological disposal conditions, and to

\footnotetext{
${ }^{a}$ The Centre for Radiochemistry Research, The School of Chemistry,

The University of Manchester, Oxford Road, Manchester, M13 9PL, UK.

E-mail: louise.natrajan@manchester.ac.uk; Tel: +44 (o)1612751426

${ }^{b}$ The Photon Science Institute, Alan Turing Building,

The University of Manchester, Oxford Road, Manchester, M13 9PL, UK

${ }^{c}$ Karlsruhe Institute of Technology (KIT), Institute for Nuclear Waste Disposal (INE),

P.O. Box 3640, 76021 Karlsruhe, Germany

${ }^{d}$ University of Heidelberg, Institute for Physical Chemistry,

Im Neuenheimer Feld 253, 69120 Heidelberg, Germany

${ }^{e}$ Department of Chemistry, University College London,

20 Gordon Street, London, WC1H OAJ, UK

$\dagger$ Electronic supplementary information (ESI) available: Full experiemental, spectroscopic and computationad detaila. CCDC 1032118 and 1032119 for compounds 1 and 2. For ESI and crystallographic data in CIF or other electronic format see DOI: $10.1039 / \mathrm{c} 4 \mathrm{cc} 08718 \mathrm{f}$

\# Current address: Department of Chemistry, Lancaster University, Lancaster, LA1 4YB, UK.
}

provide insight into the mechanisms behind promising bioremediation techniques for the immobilisation of aquatically mobile uranyl(vi) species. ${ }^{2,6}$ Laser induced emission spectroscopy of uranyl(vi) is also being used for its identification in aqueous wastes, in future sustainable partitioning and transmutation closed fuel cycles and in situations where the concentration and volume of the sample is too small (and the activity too high to consider concentration) for other analytical techniques to be of use.

The lack of analogous reports involving neptunyl (and plutonyl) ions is due in part to the relative redox instability of these ions in aqueous solutions ( $c f$. uranyl(vi)). ${ }^{7}$ There are very few neptunyl(vi) compounds that are redox stable in solution since neptunyl(v) is the most stable oxidation state, especially in aqueous (and therefore in most environmental and reprocessing) conditions. The relative proportion of each oxidation state ( $\mathrm{r}, \mathrm{v}$ and $\mathrm{vI})$ is heavily dependent on sample $\mathrm{pH}$. In non-aqueous conditions, the $+\mathrm{v}$ oxidation state also predominates; the neptunyl(vi) chloride salt $\left[\mathrm{NpO}_{2} \mathrm{Cl}_{2}(\text { thf })\right]_{n}$ undergoes partial reduction in thf solution over several days producing an isolable mixed oxidation state neptunyl(v)-(vi) salt, ${ }^{8}$ whereas in $\mathrm{MeOH}$, rapid reduction to neptunyl(v) is observed. Clark reported that the addition of 18-crown-6 to perchloric or triflic acid solutions of $\mathrm{NpO}_{2}(\mathrm{vI})$ ions resulted in the isolation of a $\mathrm{NpO}_{2}(\mathrm{v})$ crown ether complex. ${ }^{9}$ Despite this, several pure oxidation state $\mathrm{NpO}_{2}(\mathrm{vI})$ complexes have been isolated. ${ }^{10,11}$

Here, we report on a redox stable neptunyl(VI) coordination compound that is prepared from both neptunyl(v) and neptunyl(vi) precursors with the ligand TPIP (tetraphenylimidodiphosphinate), ${ }^{12}$ that may well serve to model solvated forms of neptunyl(vi), in that no redox active ligands are present (eqn (1)). Previously, we reported that TPIP reacts with uranyl(vi) salts to yield discrete monometallic, bimetallic and trimetallic complexes $\left[\mathrm{UO}_{2}(\mathrm{TPIP})(\right.$ thf $\left.)\right],\left[\mathrm{UO}_{2}(\mathrm{TPIP})-\right.$ $\left.\left(\mathrm{Cy}_{3} \mathrm{PO}\right)\right],\left[\mathrm{UO}_{2}(\mathrm{TPIP})_{2}\right]_{2}$ and $\left[\mathrm{UO}_{2}(\mathrm{TPIP})_{2}\right]_{3} \cdot{ }^{13}$ Each uranyl(VI) ion possesses a unique luminescent fingerprint of emission maxima, spectral shape and radiative lifetimes to characterise the nuclearity and type of each complex. Limiting the absorption envelope of the chromophoric groups in the TPIP ligand to the UV (phenyl groups and relatively localized $\left[\mathrm{N}^{-}-\mathrm{P}-\mathrm{O}\right]$ double bonds) gives rise to strongly emissive compounds in fluid solution at room temperature by 
inhibiting competitive back energy transfer processes from the emissive uranyl(vi) LMCT state. We reasoned that the same principles should apply for neptunyl(vi).

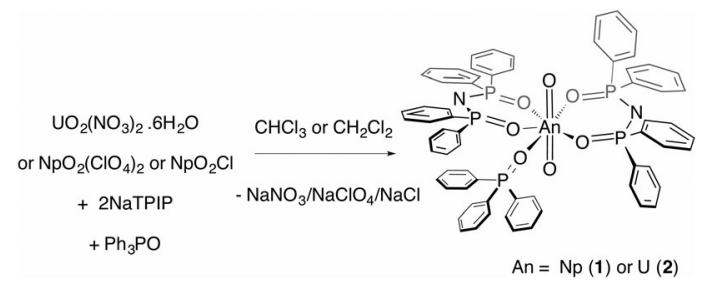

Treatment of neptunyl(v) chloride with two equivalents of NaTPIP and one of $\mathrm{Ph}_{3} \mathrm{PO}$ in mixtures of chloroform and methanol (10-50\% methanol) resulted in quantitative conversion to the neptunyl(vi) complex $\left.\left[\mathrm{NpO}_{2} \text { (TPIP }\right)_{2}\left(\mathrm{Ph}_{3} \mathrm{PO}\right)\right]$ (1). The same complex can also be prepared from $\left[\mathrm{NpO}_{2}\left(\mathrm{ClO}_{4}\right)_{2}\right]$ in chloroform. The complete oxidation of $\left[\mathrm{NpO}_{2} \mathrm{Cl}\right]$ in the presence of TPIP and $\mathrm{Ph}_{3} \mathrm{PO}$ in organic solvents upon crystallisation is surprising and even in 50\% methanol:chloroform solutions, $\mathbf{1}$ can be prepared and isolated. Moreover, $\mathbf{1}$ is stable with respect to reduction in $100 \%$ halogenated solvents for an indefinite time period (monitored for 9 months) as confirmed by UV-vis-nIR absorption spectroscopy. A principal f-centred absorption at $1232 \mathrm{~nm}$ characteristic of $\mathrm{NpO}_{2}(\mathrm{vI})$ is observed and no significant absorptions at $980 \mathrm{~nm}$ that are typical for $\mathrm{NpO}_{2}(\mathrm{v})$ are present. $\dagger^{8-11,14}$

The ${ }^{31} \mathrm{P}$ solution NMR spectrum of $\mathbf{1}$ in $\mathrm{CDCl}_{3}$ shows a sharp resonance at $29 \mathrm{ppm}$ and two broader resonances at 21 and -29 ppm (assigned as unbound $\mathrm{Ph}_{3} \mathrm{PO}, 29 \mathrm{ppm}$, and complexed $\mathrm{Ph}_{3} \mathrm{PO}$ and TPIP) indicating slow exchange of monodentate $\mathrm{Ph}_{3} \mathrm{PO}$ on the experimental timescale. $\dagger$ This chemical exchange was also corroborated by 2D ${ }^{1} \mathrm{H}$ diffusion ordered spectroscopic (DOSY) measurements, where in $\mathbf{1}$, two species with diffusion coefficients of $6.7(2) \times 10^{-10} \mathrm{~m}^{2} \mathrm{~s}^{-1}$ and $c a .14 \times 10^{-10} \mathrm{~m}^{2} \mathrm{~s}^{-1}$ are discernible at $295 \mathrm{~K} . \dagger$ The most broadened and downfield shifted proton resonances belong to a faster diffusing species (here, $\mathrm{Ph}_{3} \mathrm{PO}$ ). The TPIP protons do not experience a large induced paramagnetic shift being more than three bonds away from the metal centre, ${ }^{12}$ but the longitudinal proton relaxation times $\left(T_{1}\right)$ are suggestive of a neptunyl $5 \mathrm{f}^{1}$ electronic configuration and range from 0.94 to $2.54 \mathrm{~s}$ at $300 \mathrm{~K}$, providing further evidence of the assignment of the $+\mathrm{VI}$ oxidation state in $1 .^{15}$ For comparison, resonances in uncomplexed $\mathrm{Ph}_{3} \mathrm{PO}$ (at $300 \mathrm{~K}$ ) have relaxation times of 3.70-4.40 s.

Yellow single crystals of $\mathbf{1}$ for X-ray diffraction analysis were grown from slow evaporation of an NMR tube reaction of $\left[\mathrm{NpO}_{2} \mathrm{Cl}\right]$ plus two equivalents of TPIP and one of $\mathrm{Ph}_{3} \mathrm{PO}$ in an $8: 1 \mathrm{v} / \mathrm{v} \mathrm{CDCl}{ }_{3}: \mathrm{MeOD}_{4}$ solution (Fig. 1). For comparative purposes, the uranyl(vi) analogue $\left[\mathrm{UO}_{2}(\mathrm{TPIP})_{2}\left(\mathrm{Ph}_{3} \mathrm{PO}\right)\right] \cdot \mathrm{CH}_{2} \mathrm{Cl}_{2}$ (2) was prepared analogously. $\dagger$

In the solid state, both complexes $\mathbf{1}$ and $\mathbf{2}$ are isostructural and the coordination geometries around the actinide cations are approximately pentagonal bipyramidal. Charge balancing together with optical and NMR data require a +vi oxidation state within the neptunium cation in 1. The neptunyl(vi) bond lengths of 1.7501(17) and $1.7470(17) \AA$ (bond angle 179.21(8) ̊) are in the range for previously seen neptunyl(vi) complexes, ${ }^{9,16}$ directly comparable to those in 2 at 1.767(3) and 1.764(3) $\AA$, with the decrease in bond length of between 0.015 and $0.020 \AA$ attributable to the actinide contraction. The Np- $\mathrm{O}_{\text {TPIP }}$ bonds are between 2.3558(16) and 2.3584(17), shorter

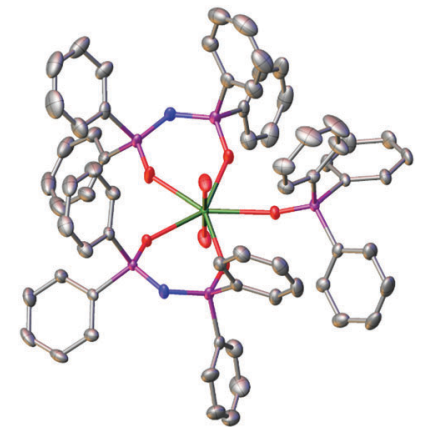

Fig. 1 Solid state molecular structure of 1 with thermal ellipsoids set at the $50 \%$ probability level; $\mathrm{H}$ atoms are omitted for clarity.

than the $\mathrm{Np}-\mathrm{O}_{\mathrm{Ph}_{3} \mathrm{PO}}$ bond length of 2.4099(16) $\AA$. Whilst this indicates a stronger bond to the TPIP ligands, this is in contrast to 2 where all the equatorial bond lengths range 2.375(3) to 2.429(3) $\AA$ $(\mathrm{O}=\mathrm{U}=\mathrm{O}$ bond angle 179.10(15) $\AA$ ).

Previous studies of the photophysical properties of the neptunyl(vi) ion have shown that emission from several excited states in the near infrared region between 1452 and $1580 \mathrm{~nm}$ can be achieved in two ways: (i) by LMCT sensitization in room temperature aqueous solution in a polyoxometalate complex (via the $\mathrm{O}$ $\rightarrow$ W LMCT transitions); ${ }^{17}$ (ii) by direct excitation into neptunyl(vi) f-centered absorption bands in a frozen glass or the solid state in $\mathrm{Cs}_{2}\left[\mathrm{NpO}_{2} \mathrm{Cl}_{4}\right]^{18}$ In both cases, the emission was assigned to interconfigurational transitions originating from excited states within the $5 \mathrm{f}^{1}$ manifold and no visible charge transfer emissions were reported.

In 1, excitation at these wavelengths (300-700 mm) in $\mathrm{CH}_{2} \mathrm{Cl}_{2}$ solution did not reveal any emission maxima in the near infrared region of the electromagnetic spectrum (using current instrumental set ups). However, excitation between 280 and $420 \mathrm{~nm}$ gave a vibrationally resolved visible emission band centred at $438 \mathrm{~nm}$. The spectral shape of this emission band is independent of excitation wavelength suggesting that the emission originates from a common excited state. The fact that the excitation and emission profiles are broad indicates that the emission feature possesses considerable charge transfer character, which is confirmed by theoretical calculations (vide infra). The reconvoluted radiative lifetime of the emission, following 375 or $405 \mathrm{~nm}$ excitation is biexponential at $1.3(95 \%)$ and $5.0(5 \%)$ ns with the short lifetime difficult to measure accurately against a scatterer and the kinetic profile is monoexponential following tail fitting; $\tau=1.5 \mathrm{~ns}$. The lifetime is significantly shorter than its uranyl(vi) counterparts in fluid solution $(1.66 \mu \mathrm{s}$ in 2$) \dagger$ and also than that reported from the $5 \mathrm{f}^{1}$ uranyl(v) ion in the literature. ${ }^{19}$ All previous reports of emission from $\mathrm{NpO}_{2}(\mathrm{v})^{20}$ and $\mathrm{NpO}_{2}$ (vi) species are short-lived (<62 ns in solution), $\S$ and emission from 1 is also expected to be short due to efficient nonradiative relaxational pathways through the $5 \mathrm{f}^{1}$ manifold. The energy spacings between the three maxima (Fig. 2) are 1349 and $1489 \mathrm{~cm}^{-1}$, are considerably higher than typical $\mathrm{Np}=\mathrm{O}_{\mathrm{yl}}$ Raman active symmetric stretch values $\left(c a .800 \mathrm{~cm}^{-1}\right)$ (ref. 7, 9 and 21) and more likely to correspond to a $\mathrm{P}-\mathrm{N}$ stretch from the TPIP ligand as measured experimentally in the $\mathrm{UO}_{2}(\mathrm{vI})$ derivative 2 (range, $1163-1211 \mathrm{~cm}^{-1}$ ). This suggests that the emissive excited state possesses significant TPIP ligand character (vide infra). Interestingly, the excitation spectra 


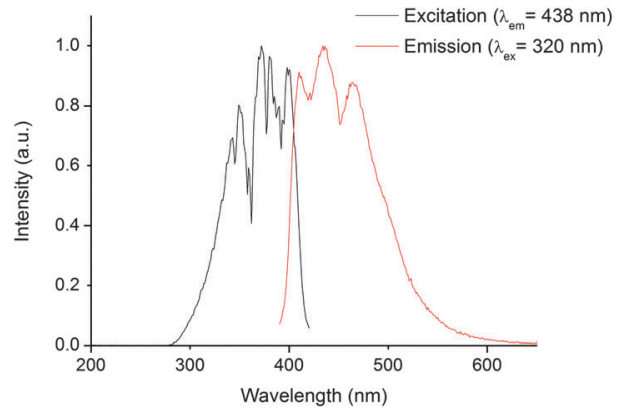

Fig. 2 Steady state excitation spectrum (black trace, recorded at the emission maxima of $438 \mathrm{~nm}$ ), and emission spectrum (red trace, recorded following $320 \mathrm{~nm}$ excitation), of 1 in $\mathrm{CH}_{2} \mathrm{Cl}_{2}$ at $295 \mathrm{~K}$.

show absorptions that correspond to previously reported UV neptunyl(vi) absorptions; ${ }^{7}$ these largely remain unassigned in the literature, but we presume these to be $\mathrm{Np}=\mathrm{O}$ 'yl' and ligand-Np (equatorial LMCT) transitions at $c a .340 \mathrm{~nm}$ and $380 \mathrm{~nm}$ in $\mathbf{1}$ respectively by analogy with uranyl(VI) TPIP complexes. ${ }^{13,22}$ Moreover, the excitation spectra show no transitions that correspond to TPIP $\pi-\pi^{*}$ absorptions, indicating that the emissive excited state is localised on the neptunyl unit itself. The possibility of the emission being phosphorescence from TPIP was also examined by recording the emission spectrum of the lanthanide analogue $\left[\mathrm{Gd}(\mathrm{TPIP})_{3}\right]$ at $77 \mathrm{~K},{ }^{12}$ which showed similar features but did not correspond exactly to the emission profile seen in $\mathbf{1}$ and additionally was very weak. $\dagger$ The similarity of these spectra do however lend further weight to the conclusion that the emission in $\mathbf{1}$ possesses considerable TPIP character. By contrast, excitation between 320 and $420 \mathrm{~nm}$ in 2 resulted in a typical highly resolved uranyl(vi) emission spectrum centred at $522 \mathrm{~nm}$ that is $100 \% \mathrm{O}_{\mathrm{yl}} \rightarrow \mathrm{U}$ LMCT in character; the apparent electronic origin of the emission $\left(E_{0-0}\right)$ was determined as $20750 \mathrm{~cm}^{-1}$ and the average vibrational progression was measured as $809 \mathrm{~cm}^{1}$ which corresponds well to the $\nu_{1}$ Raman active symmetric uranyl stretch determined from experiment $\left(825 \mathrm{~cm}^{-1}\right)$ and no additional $(\mathrm{P}-\mathrm{N})$ vibrational coupling was apparent. The excitation spectrum of 2 recorded at the emission maxima is however a combination of TPIP $\rightarrow \mathrm{U}$ and $\mathrm{O}_{\mathrm{yl}} \rightarrow \mathrm{U} \mathrm{LMCT.}^{13} \dagger$

In order to verify the origin of vibrational fine structure in the emission spectrum of $\mathbf{1}$, we performed a set of density functional theory (DFT) calculations on simplified structures in which phenyl groups were replaced with terminating hydrogens and solvation effects included via the COSMO implicit solvent model. These calculations, performed using version 6.4 of the TURBOMOLE code,${ }^{23}$ employed the hybrid-GGA PBE0 (ref. 24) exchange correlation functional and Ahlrichs-style basis sets of polarised triple- $\xi$ quality. ${ }^{25}$ Structural characterisation provided excellent agreement with crystallographic data, with An- $\mathrm{O}_{\mathrm{yl}}$ bond lengths accurate to better than $0.01 \AA$ and a calculated contraction of the An- $\mathrm{O}_{\mathrm{yl}}$ bond of $0.026 \AA$ when comparing the $\mathrm{UO}_{2}(\mathrm{vI})$ and $\mathrm{NpO}_{2}(\mathrm{vI})$ complexes. Equatorial coordination was also well reproduced, with an average $\mathrm{Np}-\mathrm{O}_{\text {TPIP }}$ bond length of $2.366 \AA$, shorter than the $2.443 \AA \mathrm{Np}-\mathrm{O}_{\mathrm{Ph}_{3} \mathrm{PO}}$ bond. Topological analysis via the quantum theory of atoms in molecules (QTAIM) $\dagger$ revealed a consistent increase in the magnitude of the electron density in the $\mathrm{Np}-\mathrm{O}_{\mathrm{TPIP}}$ bonding region when compared to the $\mathrm{Np}-\mathrm{O}_{\mathrm{Ph}_{3} \mathrm{PO}}$ bond, commensurate with the stronger bonding determined experimentally.
Vibrational frequency analysis revealed the $\mathrm{Np}-\mathrm{O}_{\mathrm{yl}}$ stretch frequencies to occur at $913 \mathrm{~cm}^{-1}$ (symmetric) and $976 \mathrm{~cm}^{-1}$ (asymmetric), significantly lower than the spacings between maxima observed in the emission spectra, however two N-P stretching modes were calculated at $1281 \mathrm{~cm}^{-1}$ and $1282 \mathrm{~cm}^{-1}$. The absence of any other modes in the region of these vibrations led us to the possibility that these N-P modes are responsible for the observed vibrational fine structure. To test this hypothesis further, time-dependent (TD-) DFT simulations of the excited states of $\mathbf{1}$ were performed. These calculations revealed several excitations in the 344-397 nm region with similar oscillator strengths of the order $10^{-4}$. Of these, three excitations, at 363, 390, and $397 \mathrm{~nm}$, had well-defined neptunyl LMCT character as well as substantial $\mathrm{N}_{\text {TPIP }}(2 \mathrm{p}) \rightarrow \mathrm{Np}(5 \mathrm{f})$ contributions of $55 \%, 22 \%$ and $20 \%$, respectively. This finding lends strong support to our assertion that the origin of the observed fine structure is due to the TPIP N-P vibrational modes and that the emission is a combination of TPIP $\rightarrow \mathrm{Np}$ and $\mathrm{O}_{\mathrm{yl}} \rightarrow \mathrm{Np}$ charge transfer.

Compounds 1 and 2 have different excitation and emission profiles as well as radiative lifetime so we reasoned that it should be possible to discriminate between the two in solution. Indeed, addition of an equimolar dichloromethane solution of 2 to a dichloromethane solution of $\mathbf{1}(0.87 \mathrm{mM})$ resulted in an emission spectrum that is a sum of the individual components (following excitation at 320 and $420 \mathrm{~nm}$ ). Interestingly, even in the presence of an excess of $2(1.47 \mathrm{mM})$, both components are easily identifiable. Further, by changing the excitation wavelength, spectral editing can be achieved such as the response of purely $\mathrm{NpO}_{2}(\mathrm{vI}),(290 \mathrm{~nm}$ excitation), $\mathrm{UO}_{2}(\mathrm{vI})(380 \mathrm{~nm}$ excitation) or a mixture of the two can be obtained ( $320 \mathrm{~nm}$ and $420 \mathrm{~nm}$ excitation, Fig. 3). In all spectra, the vibrational progression of each individual actinyl(vi) cation is evident suggesting no loss in structural integrity in $\mathbf{1}$ and $\mathbf{2}$.

The kinetic profile of both components in fluid solution at room temperature, following $420 \mathrm{~nm}$ excitation, is multiexponential and the major component $(50 \%)$ possesses a radiative lifetime of $5 \mathrm{~ns}$. The lifetimes of the minor components are $1 \mathrm{~ns}(23 \%)$ and $18 \mathrm{~ns}$ $(24 \%) . \dagger$ Moreover, the time resolved emission spectra show the dominance of $\mathrm{NpO}_{2}(\mathrm{vI})$ emission at short delay times ( 0 to $25 \mathrm{~ns}$ ) and only $\mathrm{UO}_{2}(\mathrm{vI})$ emission at longer delay times (30 to $100 \mathrm{~ns}$ ), meaning that the longer lived component can be assigned to $\mathrm{UO}_{2}(\mathrm{vI})$ emission. $\dagger$ The short lifetimes for the mixed solution of $\mathbf{1}$ and 2

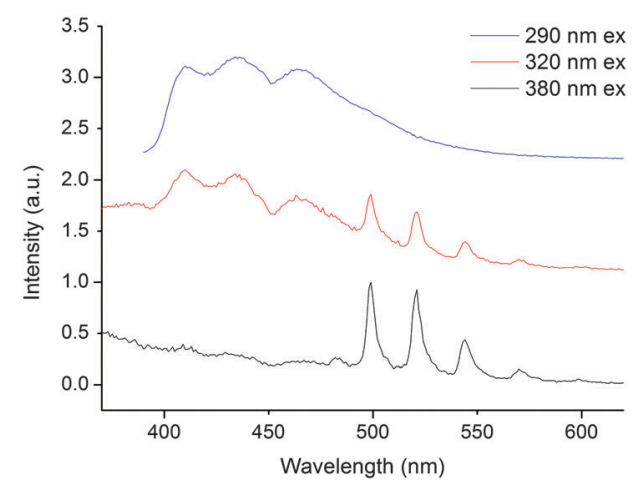

Fig. 3 Steady state emission spectra of a mixture of $1(0.87 \mathrm{mM})$ and 2 (1.47 mM) following $290 \mathrm{~nm}$ excitation (blue trace), $320 \mathrm{~nm}$ excitation (red trace) and $380 \mathrm{~nm}$ excitation (black trace) in $\mathrm{CH}_{2} \mathrm{Cl}_{2}$ at $295 \mathrm{~K}$. 
suggests an efficient competitive pathway for emission quenching and the two complexes may be interacting with one another in solution. Overlap of the higher energy $\mathrm{NpO}_{2}(\mathrm{vI})$ charge transfer bands with TPIP absorption in the UV-vis spectrum means that the absorption maxima corresponding to the emission are obscured. This precludes the determination of a quantum yield and experimentally, the exact origin of the emission.

The ${ }^{31} \mathrm{P},{ }^{1} \mathrm{H}$ NMR and ${ }^{1} \mathrm{H}$ DOSY-NMR spectra also strongly suggest the two complexes may be aggregated in solution via loss of the $\mathrm{Ph}_{3} \mathrm{PO}$ ligands; the $1 \mathrm{D}$ spectra are broadened at $295 \mathrm{~K}$ when compared to the individual complexes with many overlapping resonances and several species are suggested by the ${ }^{1} \mathrm{H}$ DOSY spectrum. $\dagger$ However, all attempts to isolate any intermediate (possible mixed metal) species were unsuccessful, producing in all cases single crystals of the most thermodynamically stable compounds 1 and 2 (and a solitary crystal of $\mathrm{Ph}_{3} \mathrm{PO}$ ). This indicates that any aggregated species is only a transient in solution. It is interesting to note that even in the presence of uranyl(vi), no redox reactions of $\mathbf{1}$ in $\mathrm{CH}_{2} \mathrm{Cl}_{2}$ solution are observed; the possibility of forming intermetallic actinyl-oxo-actinide interactions between $\mathrm{NpO}_{2}(\mathrm{vI})$ and $\mathrm{UO}_{2}(\mathrm{VI})^{26}$ may be expected to be favourable, especially given that TPIP can promote such interactions with uranyl(vI). ${ }^{13}$

In conclusion, the neptunyl(vi) complex $\left[\mathrm{NpO}_{2}(\mathrm{TPIP})_{2}\left(\mathrm{Ph}_{3} \mathrm{PO}\right)\right]$, (1, where TPIP $=$ tetraphenylimidodiphosphinate $)$ has been prepared from both $\mathrm{NpO}_{2}(\mathrm{v})$ and $\mathrm{NpO}_{2}(\mathrm{vI})$ precursors and has been found to be indefinitely redox stable in chlorinated solvent solutions. The ligand TPIP is not redox-active, lacks peripheral chromophores in the visible region, and therefore enables us to detect the vibrationally resolved visible emission of the $\mathrm{NpO}_{2}$ (v) cation in $\mathbf{1}$ for the first time. A combination of experimental evidence and DFT calculations has enabled the assignment of the emission to be a combination of $\mathrm{O}_{\mathrm{yl}} \rightarrow \mathrm{Np}$ LMCT and TPIP $\rightarrow \mathrm{NpO}_{2}$ LMCT emission (20 to 55\%). Moreover, in an equimolar solution of $\mathbf{1}$ and its uranyl(vI) counterpart, 2, time resolved studies suggest that the two complexes may be aggregated in fluid solution and there is a cooperative pathway for emission quenching. Both broadband and selective excitation and time gating leads to spectral editing and this study illustrates that selective detection and discrimination of individual actinide cations is possible using time resolved emission techniques. We are currently investigating the effects of electron withdrawing and donating substituents in TPIP analogues to assess the relative contributions of the TPIP and $\mathrm{Np}=\mathrm{O}$ LMCT on the emission of $\mathrm{NpO}_{2}(\mathrm{vI})$ compounds.

The authors gratefully acknowledge Simon Randall for help with the crystallographic data and Professor David Collison for helpful discussions. We thank the EPSRC for funding a Career Acceleration Fellowship (LSN and AK), postdoctoral funding (ANS), and studentships (SDW and PDP), The Royal Society for an equipment grant and The University of Manchester for support. The authors thank the European Commission Euratom FP7 funded project (no. 269923) EURACT-NMR for support.

\section{Notes and references}

$\S$ It is worth noting here that the nIR emisison of the $\mathrm{NpO}_{2}(\mathrm{vI})$ aqua ion has not been dectected directly but the radiative lifetime has been estimated to be $7.6 \mathrm{~ns}$ (ref. 17).
1 For recent reviews, see: M. Altmaier, X. Gaona and T. Fanghänel, Chem. Rev., 2013, 113, 901; K. Maher, J. R. Bargar and J. E. Brown Jr., Inorg. Chem., 2013, 52, 510; L. S. Natrajan, A. N. Swinburne, M. B. Andrews, S. Randall and S. L. Heath, Coord. Chem. Rev., 2014, 266-267, 171.

2 L. S. Natrajan, Coord. Chem. Rev., 2012, 256, 1583.

3 R. G. Denning, Struct. Bonding, 1992, 79, 215; R. G. Denning, J. Phys. Chem. A, 2007, 111, 4125.

4 J. Su, W. H. E. Schwarz and J. Li, Inorg. Chem., 2012, 51, 3231.

5 See for example: T. Arnold, S. Utsunomiya, G. Geipel, R. C. Ewing, N. Baumann and V. Brendler, Environ. Sci. Technol., 2006, 40, 4646; E. J. Elzinga, C. D. Tait, R. J. Reeder, K. D. Rector, R. J. Donohoe and D. E. Morris, Geochim. Cosmochim. Acta, 2004, 68, 2437; K. F. Smith, N. D. Bryan, A. N. Swinburne, P. Bots, S. Shaw, L. S. Natrajan, J. F. W. Mosselmans, F. R. Livens and K. Morris, Geochim. Cosmochim. Acta, 2015, 148, 343.

6 K. H. Williams, J. R. Bargar, J. R. Lloyd and D. R. Lovley, Curr. Opin. Biotechnol., 2013, 24, 489; K. Grossman, T. Arnold, E. KrawczykBarsch, S. Diessner, A. Wobers, G. Benhard and R. Krawietz, Environ. Sci. Technol., 2007, 41, 6498.

7 J. C. Hindman, L. B. Magnusson and T. J. LaChapelle, J. Am. Chem. Soc., 1949, 71, 687; R. Sjoblom and J. C. Hindman, J. Am. Chem. Soc., 1951, 73, 1744; H. A. Friedman and L. M. Toth, J. Inorg. Nucl. Chem., 1980, 42, 1347; T. W. Newton, D. E. Hobart and P. D. Palmer, The Preparation and Stability of Pure Oxidation States of Neptunium, Plutonium, and Americium, Los Alamos National Laboratory, 1986, LA-UR-86-967.

8 S. M. Cornet, L. J. L. Häller, M. J. Sarsfield, D. Collison, M. Helliwell, I. May and N. Kaltsoyannis, Chem. Commun., 2009, 917.

9 D. L. Clark, D. W. Keogh, P. D. Palmer, B. L. Scott and C. D. Tait, Angew. Chem., Int. Ed., 1998, 37, 64.

$10\left[\mathrm{NpO}_{2}(\mathrm{DPMMO})_{2} \mathrm{Cl}\right]_{2}\left[\mathrm{NpO}_{2} \mathrm{Cl}_{4}\right](\mathrm{DPPMO}=$ bis(diphenyl-phosphino)methanedioxide) S. M. Cornet, M. P. Redmond, D. Collison, C. A. Sharrad, M. Helliwell and J. Warren, C. R. Chim., 2010, 13, 832.

11 Neptunyl(vi) bis(salicylidene)ethylenediamine (salen) is prepared from neptunyl(v) in methanol. D. G. Chuguryan, V. I. Dzyubenko, M. S. Grigoriev, A. I. Yanovski and Y. T. Struchkov, Radiokhimiya, 1988, 30, 41.

12 S. W. Magennis, S. Parsons and Z. Pikramenou, Chem. - Eur. J., 2002, 8, 5761.

13 M. P. Redmond, S. M. Cornet, S. D. Woodall, D. Whittaker, D. Collison, M. Helliwell and L. S. Natrajan, Dalton Trans., 2011, 40, 3914.

14 P. G. Hagan and J. M. Cleveland, J. Inorg. Nucl. Chem., 1966, 28, 2905.

15 In related neptunyl(v) TPIP solutions, the $T_{1}$ values of the proton resonances are of millisecond order $(10-110 \mathrm{~ms})$. S. D. Woodall, $\mathrm{PhD}$ thesis, The University of Manchester, 2014.

16 M. P. Wilkerson, H. J. Dewey, P. L. Gordon and B. L. Scott, J. Chem. Crystallogr., 2004, 34, 807; N. W. Alcock, M. M. Roberts and D. Brown, J. Chem. Soc., Dalton Trans., 1982, 25.

17 C. Talbot-Eeckelaers, S. J. A. Pope, A. J. Hynes, R. Copping, C. J. Jones, R. J. Taylor, S. Faulkner, D. Sykes, F. R. Livens and I. May, J. Am. Chem. Soc., 2007, 129, 2442.

18 M. P. Wilkerson and J. M. Berg, J. Phys. Chem. A, 2008, 112, 2515; M. P. Wilkerson and J. M. Berg, Radiochim. Acta, 2009, 97, 223.

19 R. Steudtner, T. Arnold, K. Grossman, G. Geipel and V. Brendler, Inorg. Chem. Commun., 2006, 9, 939.

20 R. Bradshaw, D. Sykes, L. S. Natrajan, R. J. Taylor, F. R. Livens and S. Faulkner, IOP Conf. Ser.: Mater. Sci. Eng., 2010, 9, 012047.

21 C. Madic, G. M. Begun, D. E. Hobart and R. L. Hahn, Inorg. Chem., 1984, 23, 1914.

22 B. Drobot, R. Steudner, J. Raff, G. Geipel, V. Brendler and S. Tsushima, Chem. Sci., DOI: 10.1039/C4SC02022G.

23 R. Ahlrichs, M. Bär, M. Häser, H. Horn and C. Kölmel, Chem. Phys. Lett., 1989, 162, 165.

24 J. Perdew, K. Burke and M. Ernzerhof, Phys. Rev. Lett., 1996, 77, 3865; C. Adamo and V. Barone, J. Chem. Phys., 1999, 110, 6158.

25 F. Weigend and R. Ahlrichs, Phys. Chem. Chem. Phys., 2005, 7, 3297.

26 S. Wang, J. Diwu, E. V. Alekseev, L. J. Jouffret, W. Depmeier and T. E. Albrecht-Schmitt, Inorg. Chem., 2012, 51, 7016; S. Skanthakumar, M. R. Antonio and L. Soderholm, Inorg. Chem., 2008, 47, 4591. 